\title{
Could the expression of CD86 and FcyRIIB on $B$ cells be functionally related and involved in driving rheumatoid arthritis?
}

\author{
Claudia Mauri* and Elizabeth C Jury \\ See related research by Catalán et al., http://arthritis-research.com/content/12/2/R68
}

\begin{abstract}
Aberrant immune responses play a pivotal role in the processes that cause inflammation and joint damage in patients with rheumatoid arthritis (RA). Polyclonal $B$ cell activation and the production of autoantibodies are immunological hallmarks of the disease. However, controversy surrounds the pathogenicity of autoantibodies, mainly because not all patients are seropositive (10\% of RA patients are seronegative), suggesting that they could be markers rather than makers of disease. Catalán and collaborators report that patients with RA display reduced expression of FcyRIIB on memory B cells and plasma cells, which inversely correlates with autoantibody levels. Considering that FcyRIIIB stimulation down-regulates antibody production, this work strengthens the link between autoantibodies and pathogenicity.
\end{abstract}

In a recent article Catalán and colleagues [1] examined the expression of FcyRIIB in naïve, memory and plasmablast $B$ cell subsets from peripheral blood of patients with rheumatoid arthritis (RA) and the results were correlated with levels of autoantibodies to cyclic citrullinated proteins (anti-CCP) detected in matching serum. Firstly, they observed reduced FcyRIIB expression in memory and plasmablast $\mathrm{B}$ cells from patients compared to the levels expressed on B cells from healthy controls. Secondly, the expression levels of FcyRIIB inversely correlated with the titre of anti-CCP antibodies in patients' serum. Indeed, RA patients with low autoantibody titres expressed higher levels of this receptor. Thirdly, they also report an increased frequency of CD86,

${ }^{*}$ Correspondence: c.mauri@ucl.ac.uk

Centre for Rheumatology Research, Department of Medicine, University College London, 46 Cleveland Street, London W1T4 JF, UK usually up-regulated upon activation, on memory and naïve B cells [2]. Intriguingly, RA patients responding to adalimumab treatment display 'normalized' levels of CD86 only on memory B cells, but not on naïve B cells, and reduced expression of FcyRIIB only on naïve B cells, but not on memory B cells, and this was accompanied by unchanged levels of anti-CCP antibodies. Although these results are based on a relatively small group of patients, they could, if confirmed, advocate the use of FcyRIIB expression coupled to anti-CCP responses as a predictive biomarker to monitor the early stage of disease and progression.

Human Fc receptors for IgG (FcyRI, Fc $\gamma$ RIIA, FcyRIIC, Fc $\gamma$ RIIIA, Fc $\gamma$ RIIIB, Fc $\gamma$ RIIB) exert different functions and have diverse affinities for the Fc fragment of IgG, and these receptors are differentially expressed by a variety of cells [3]. B cells, however, exclusively express FcyRIIB, an inhibitory receptor that binds IgG immune complexes and negatively regulates $B$ cell receptor activation. FcyRIIB is able to suppress or block B cell receptor activation by transmitting inhibitory signals via its cytoplasmic immunoreceptor tyrosine-based inhibitory (ITIM) motif upon simultaneous engagement with the $\mathrm{B}$ cell receptor [3]. Thus, reduced levels of these regulatory proteins could result in a lower threshold for B cell activation and stronger activating signals following $B$ cell receptor cross-linking.

Strong evidence supports the hypothesis that Fc $\gamma$ RIIB and IgG immune complexes may play a central role in the regulation of humoral responses, and that the defects in this system could contribute to the development of autoimmunity. There is evidence that FcyRIIB preferentially limits activation of high affinity autoreactive B cells in the periphery [4]. Indeed, mice lacking the FcyRIIB receptor develop exacerbated autoimmunity compared to wild-type mice [5]. Furthermore, when the pathogenicity of human RA-associated autoantibodies was tested by passive transfer into mice deficient for FcyRIIB, mice developed inflammation and histological lesions consistent with arthritis, supporting a direct role for humoral 
immunity in the development of autoimmune arthritis [6].

The link between the inhibitory Fc $\gamma$ RIIB and the modulation of B cell activity and humoral tolerance has also been translated into humans. Expression of FcyRIIB was found to be considerably decreased in memory B cells from patients with systemic lupus erythematosus compared to the levels detected in healthy controls. This directly correlated with decreased FcyRIIB-mediated suppression of B cell receptor-induced down-stream signalling events [7]. Furthermore, several studies link FcyRIIB polymorphisms to increased susceptibility to systemic lupus erythematosus [8] and with joint damage in patients with RA [9]. However, although it seems a likely candidate, a direct role for inhibitory FcyRIIB in the pathogenesis of RA has not been demonstrated.

FcyRIIB is differentially expressed on healthy B cells, depending on the stage of $B$ cell development and, since FcyRIIB helps to regulate B cell receptor-mediated stimulatory signals, it acts as a gatekeeper controlling $B$ cell proliferation and maturation [10]. However, the results presented by Catalán and colleagues did not show any stringent relationship between $B$ cell activation measured by CD86 expression and levels of FcyRIIB, indicating that the relationship between FcyRIIB expression and B cell activation, especially in the context of inflammatory disease, requires further exploration. The results presented by Catalán and colleagues go some way to support the hypothesis that RA is associated with decreased negative feedback of humoral and effector immune responses. In addition, although not formally proven, it is tempting to speculate that the increased levels of CD86 expression on naïve B cells may be involved in and precede the down-regulation of FcyRIIB on memory B cells. Less clear is why in a less inflamed environment (that is, after anti-TNF $\alpha$ treatment) the expression of Fc $\gamma$ RIIB is not recovered to similar levels to those detected in healthy individuals.

Defects in other inhibitory receptors have also been linked with RA pathogenesis, including reduced expression of CTLA-4 (cytotoxic T-lymphocyte antigen 4) in regulatory $\mathrm{T}$ cells from patients [11]. In the case of CTLA-4, reduced expression was also associated with abnormal function, but it remains to be seen whether FcyRIIB-mediated signalling is fully functional in B cells from RA patients. Abnormal FcyRIIB function could go some way to explain the discrepancy between FcyRIIB expression and B cell activation as determined by CD86 expression.
Finally, if FcyRIIB truly acts as a late checkpoint at the level of class-switched B cells or antibody-producing plasmablasts/plasma cells, and considering that autoreactive $\mathrm{B}$ cells are generated during the process of affinity maturation, then the relationship between FcyRIIB expression in autoantibody-mediated disease such as RA merits further exploration. Indeed, differential Fc $\gamma$ RIIB expression may influence other B cell functions, including antigen presentation and cytokine production, involved in RA pathogenesis.

\section{Abbreviations}

$C C P=$ cyclic citrullinated protein; $\mathrm{RA}=$ rheumatoid arthritis.

Competing interests

The authors declare that they have no competing interests.

Published: 13 August 2010

References

1. Catalán D, Aravena O, Sabugo F, Wurmann P, Soto L, Kalergis AM, Cuchacovich M, Aguillon JC, for Millenium Nucleus on Immunology and Immunotherapy P-07-088-F: B cells from rheumatoid arthritis patients show important alterations in the expression of CD86 and FcyRllb, which are modulated by anti-tumor necrosis factor therapy. Arthritis Res Ther 2010, 12:R68.

2. O'Neill SK, Cao Y, Hamel KM, Doodes PD, Hutas G, Finnegan A: Expression of CD80/86 on $B$ cells is essential for autoreactive $T$ cell activation and the development of arthritis. J Immuno/ 2007, 179:5109-5116.

3. Nimmerjahn F, Ravetch JV: Fc[gamma] receptors as regulators of immune responses. Nat Rev Immuno/ 2008, 8:34-47.

4. Venkatesh J, Kawabata D, Kim S, Xu X, Chinnasamy P, Paul E, Diamond B, Grimaldi CM: Selective regulation of autoreactive B cells by FcgammaRIIB. J Autoimmun 2009, 32:149-157.

5. Takai T: Roles of Fc receptors in autoimmunity. Nat Rev Immunol 2002, 2:580-592.

6. Petkova SB, Konstantinov KN, Sproule TJ, Lyons BL, Awwami MA, Roopenian DC: Human antibodies induce arthritis in mice deficient in the low-affinity inhibitory lgG receptor Fc $\hat{l}^{3} R I I B$. J Exp Med 2006, 203:275-280.

7. Mackay M, Stanevsky A, Wang T, Aranow C, Li M, Koenig S, Ravetch JV, Diamond B: Selective dysregulation of the FcyRIIB receptor on memory B cells in SLE. J Exp Med 2006, 203:2157-2164.

8. Floto RA, Clatworthy MR, Heilbronn KR, Rosner DR, MacAry PA, Rankin A, Lehner PJ, Ouwehand WH, Allen JM, Watkins NA, Smith KG: Loss of function of a lupus-associated FcgammaRllb polymorphism through exclusion from lipid rafts. Nat Med 2005, 11:1056-1058.

9. Radstake TR, Franke B, Wenink MH, Nabbe KC, Coenen MJ, Welsing P, Bonvini E, Koenig S, van den Berg WB, Barrera P, van Riel PL: The functional variant of the inhibitory Fcgamma receptor IIb (CD32B) is associated with the rate of radiologic joint damage and dendritic cell function in rheumatoid arthritis. Arthritis Rheum 2006, 54:3828-3837.

10. Nimmerjahn F, Ravetch JV: Fcgamma receptors: old friends and new family members. Immunity 2006, 24:19-28.

11. Flores-Borja F, Jury EC, Mauri C, Ehrenstein MR: Defects in CTLA-4 are associated with abnormal regulatory $T$ cell function in rheumatoid arthritis. Proc Natl Acad Sci U S A 2008, 105:19396-19401.

doi:10.1186/ar3092

Cite this article as: Mauri C, Jury EC: Could the expression of CD86

and FCYRIIB on B cells be functionally related and involved in driving rheumatoid arthritis? Arthritis Research \& Therapy 2010, 12:133. 